\title{
Pythagoras 1:3, an expression of the finite universe of mathematics
}

\author{
Vinoo Cameron \\ Hope research, Athens, Wisconsin, USA \\ *Corresponding author E-mail: Hope9900@frontier.com
}

\begin{abstract}
The author has published several papers which are may be hard to understand and stand as a testament to the discovery of 1:3 mathematics which is an absolute accommodation of numbers, prime numbers placement, and precise angles. The author has published a continuous Prime sieve at the divergence of $(5 / 6,1 / 6)$ and $(1 / 3$ and $2 / 3)$, a final attempt is made here to communicate the simple mathematics of the finite universe of mathematics to the dead current mathematics, that in the authors opinion is dead to the absolute reality of mathematics, as a form of approximate mathematics and has offered this manuscript for review at any mathematical venue. This discussion is about $1: 3$ Pythagoras $(\sqrt{ } 1+\sqrt{ } 9=\sqrt{ } 10$ hypotenuse $)$ and points to the clear mathematical relationship between 19 and $3^{\wedge} 2$. The span of the divergence at $1: 3$ is clearly $2+1 /\left(3^{\wedge} 2\right)$ from the base of 2 . Current mathematics is currently operating in the approximation of their myriad current theory, and they seem content.
\end{abstract}

Keywords: Pythagorean 1:3, configuration of 1(5/6, 1/6:1/3, 2/3), Arabic numerical $\left(1^{\wedge} 2-3^{\wedge} 2\right)$.

\section{Introduction}

This is expressed by the ten published papers referenced below, the divergence of this angle is in the configuration of a cone in two planes, one of these planes is represented by the $1 / 3+2 / 3=1$, and the other plane is represented by $1 / 6$ $+5 / 6 .=1$ As shown previously the 1:3 divergences accommodates the numbers naturally, and the equalization of numbers is at $4: 12(1: 3)$ as shown in the last paper on end calculus. $5+11+17=9+11+13(17-5=12 ; 13-9=4)$

\section{Mathematics}

The Arabic numerical define numerals from $1^{\wedge} 2-3^{\wedge} 2(1-9)$. Pythagoras at $1: 3$ represents the squared expression of the Arabic numerals $\left(1^{\wedge} 2+3^{\wedge} 2\right)=\sqrt{ }(10)$.

There is not much explaining to be done here here as the author does not feel obliged to explain the simplicity of his work any further for a mathematics that excels at approximations (whole numbers are absolute).

$3^{\wedge} 2=9$, a square with sides of 3 each

Reciprocal Value $=1 /\left(3^{\wedge} 2\right)=0.111111111111$.

Now in applying the Pythagoras theorem to the square, a linear advancement of 3 is in one plane, followed by ascension of 1 in the perpendicular plane, which yields a diagonal hypotenuse of $\sqrt{ }(10)$.

$$
\begin{aligned}
& \int\left[2 .+\frac{1}{3^{2}}\right]-2 \cdot \int_{\frac{n-1}{9}}^{19} 1: 3 \\
& {[\sqrt{ }(10)]^{\wedge} 2-[\sqrt{ }(9)]^{\wedge} 2=1} \\
& 10^{\wedge} 2-9^{\wedge} 2=19 \\
& 19 / 19=1 \\
& (19-1) / 9=2 \\
& 100^{\wedge} 2-81^{\wedge} 2=3439 \\
& 3439 / 19=181 \\
& (3439-1) / 9=382
\end{aligned}
$$




\section{Conclusion}

From above whole number values

$\left(2.1111111111^{*} 3^{\wedge} 2=19\right)$,

It is obvious that the end finite value will be

$2+1 /\left(3^{\wedge} 2\right)=2.11111111111 \ldots 19 / 9=2.1111111111111111 \ldots$

Because the very basis of the equation at the Pythagoras $1: 3$, is -1 , the logical understanding of this is as follows. The final finite value will be. $\mathrm{nf}$ is the finite number at the zenith

$\left(\frac{\mathrm{nf}-1}{3^{2}}\right) /\left(\frac{\mathrm{nf}}{19}\right)=2+\frac{1}{3^{2}}$

$\left(\frac{\mathrm{n}-1}{3^{2}}\right) /\left(\frac{\mathrm{n}}{19}\right)=2$

Ascension of 1 at perpendicular from 3 forward in a plane:

$3.16227766017-3=0.16227766017$

Thus 1 :(A): 0.16227766017

Reciprocal of above:

$(1 / 1):(A):(1 / 0.16227766017)=6.16227766017$

$(1-1)=6.16227766017-0.16227766017[=](6)$, the convergence value is 6 and the divergence value is $3.16227766017-$ $0.162277017[=] 3$ and the end coordinate is $1 / 3^{\wedge} 2$. In the Pythagoras triangle $+1[=](3)$ and $(1-1 / 1)[=](6) .(1-1 / 1)$ is 1 minus its reciprocal, it is zero.

This is serious as we did show in our published papers that the ascension of 1:3 at mathematical angle 19 is the fit for all numbers and the Prime numbers placement at $1: 3$, as the prime numbers sieve out at this proportion. Now it is not coincidental that angle 19 is literally a fit for angles too. In this case of Pythagoras $\left(1^{\wedge} 2+3^{\wedge} 2=\sqrt{ } 10\right)$, the angles are 90 , 19,71 degrees

$$
\begin{aligned}
& \left(\frac{90}{19}\right) *\left(\frac{19}{9}\right)=10 \\
& \left(\frac{90}{19}\right)-\left(\frac{71}{19}\right)=1 \\
& \left(\frac{90}{19}\right) *\left(\frac{19}{10}\right)=9 \\
& \frac{\sqrt{90}}{\sqrt{10}}=3
\end{aligned}
$$

P.S This Mathematician is tired of the ineptitude of mathematicians from the elite of Mathematics. The 1:3 does fit the angles and numbers as is clearly shown. The 1:3 configurations which is the basis of all mathematics, numbers, angles is now represented in museum pieces representing this mathematics, destined as a donation for the museums in Chicago and we have priced their museum value at 5 million dollars. Current mathematics is approximate at best along with its myriad theories unless they understand the lay of the 1:3 Pythagoras theorems. As to the Prime number sieve, the den Otter prime sieve has been referenced, and this dairy farmer who has done this sieve remains unknown because current mathematics is too engrossed in its drama of large prime numbers.

The following diagram shows the ascension of 1:3 Pythagoras, the 1:6 expansion of a perfect circle: The ratio 1:6 is a fixed ratio, remember $+1=3 ;(1-1 / 1)=6$ 


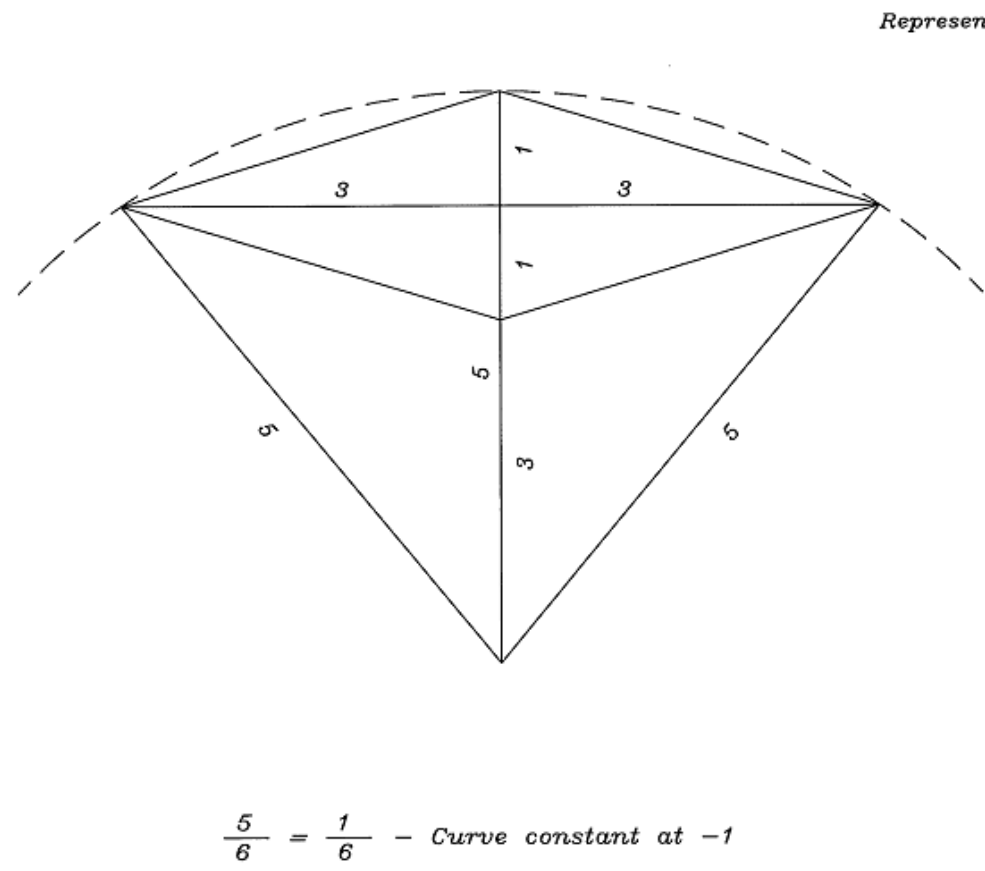

Fig. 1

\section{Acknowledgements}

1) Jesus Christ for his grace and the inspiration of the blessed Virgin Mary first and foremost in my case (And due respect for all the good in all religions, including Islam, Buddhism, Hinduism, Judaism, Sikhism) who gave the author humility, wisdom, inspiration and standing amongst all the so called super mathematicians, by his special grace, truth, to throw the "houlihan"of mathematics. (A cowboy's lasso).

2) Dr. Belal Mohammed Batiha, $\mathrm{PhD}$, a magnanimous humble mathematician and human being to the author.

3) Dr. Hong Ma, PhD, the brave editor of Journal of American science, for his pragmatism that the best ideas come from the least expected sources

4) My long suffering wife Janice Kay, a thank you for simple mathematical insights.

5) IJAMR, for its integrity and open mindedness; unlike many other journals in mathematics, they do not pinch the nostrils of creativity, neither do they direct the milk of liberty in the sciences into their own suckers. Knowledge is for the free, not the elite.

\section{References}

[1] Cameron. V. The first ever precise predictive prime number placement, International journal of applied mathematics research 2(3) (2013)345351) (journal listed by the American mathematics) society)

[2] Cameron. V. The spiral code of prime numbers, International journal of applied Mathematics research 2 (2) (2013)279-292)

[3] Cameron. V. The unified Theorem at -1 (Vedic Zero), International Journal of Mathematics research, 2(2) (2013) 221-251)

[4] Cameron.V, The disproof and fall of the Riemann's hypothesis by quadratic base: The correct variable distribution of prime numbers by the clear mathematics of the half-line values ("Chan function") of prime numbers, International Journal of Applied Mathematical Research, 2 (1) (2013) 103-110.

[5] Cameron V, den Otter T. Prime numbers 2012. Jam Sci 2012; 8(7):329-334]. (ISSN: 1545-1003), http://www.jofamericanscience.org.

[6] Cameron V, Prime number Coordinates and calculus J Am Sci, 2012; 8(10):9-10]. (ISSN: 1545-1003).http://www.jofamericanscience.org

[7] Cameron: Prime number19, Vedic Zero and the fall of western mathematics by theorem. International journal of applied mathematical research 2(1) (2013)111-115

[8] Cameron: The rational variability of all empty space by prime number: International journal of applied mathematical research, 2(2) (2013)157174

[9] Cameron: The poison pill of current mathematics theory, delivered: International journal of applied mathematical research; 2(3) (2013)387402)

[10] The End calculus of mathematics and Prime numbers: International journal of Applied Mathematics, 2(4) (2013)423-438. 